Franz von Kutschera

Grundfragen der Erkenntnistheorie 

Franz von Kutschera

Grundfragen der

Erkenntnistheorie

$W$
$\mathrm{DE}$
$\mathrm{G}$

Walter de Gruyter - Berlin · New York 1982 
CIP-Kurztitelaufnabme der Deutschen Bibliothek

\section{Kutschera, Franz von}

Grundfragen der Erkenntnistheorie / Franz von Kutschera.

- Berlin; New York: de Gruyter, 1981.

(De Gruyter-Studienbuch)

ISBN 3-11-008777-4 brosch.

ISBN 3-11-008663-8 geb.

(C) Copyright 1981 by Walter de Gruyter \& Co., vormals G. J. Goschen'sche Verlagshandlung - J. Guttentag, Verlagsbuchhandlung - Georg Reimer Karl J. Trübner - Veit \& Comp., Berlin 30. Printed in Germany -

Alle Rechte des Nachdrucks, der photomechanischen Wiedergabe, der Herstellung von Photokopien - auch auszugsweise vorbehalten.

Satz: Dörlemann-Satz GmbH \& Co. KG, Lemförde, Druck: Werner Hildebrand, Berlin 65, Einband: Luderitz \& Bauer, Berlin, 61 


\section{Meinem Vater \\ Kurt Freiherr von Kutschera \\ *28. 2. $1900 \dagger$ 13.9. 1943 zum Gedenken}


